\title{
Mural Squamous Odontogenic Tumor in a Primordial Cyst
}

\author{
Tetsuo Shimoyama, Norio Horie, Takahiro Kaneko, Tsubura Suzuki, Yasuhiko Tanebayashi, \\ Toshifumi Ozawa and Fumio Ide
}

(Received 9 January and accepted 21 February 1995)

Key words: squamous odontogenic tumor, odontogenic cyst, odontogenic tumor

\begin{abstract}
An additional case of mural squamous odontogenic tumor in a mandibular primordial cyst is reported and its clinicopathologic features are described.
\end{abstract}

\section{Introduction}

Since Pullon et al. ${ }^{[1]}$ reported 6 cases of a previously undescribed lesion under the name squamous odontogenic tumor (SOT) in 1975, SOT has been accepted as a distinct entity among odontogenic tumors ${ }^{[2,3]}$. Histologically identical lesions have been noted adjacent to the lining of several odontogenic cysts ${ }^{[4-11]}$. We report an additional case of mural SOT in the wall of a mandibular primordial cyst.

\section{Case report}

A 19-year-old man was referred by his dentist to the oral surgery clinic at Saitama Medical Center in October, 1986, because of painless swelling in the right maxilla. Intraoral examination showed a fluctuant tender swelling in the right second molar region. Radiographic studies showed a large unilocular radiolucent lesion containing an impacted second molar. Moreover, another sharply defined radiolucent lesion was noted in the third molar region of the left mandible (Fig. 1). The clinical diagnosis was multiple jaw cysts. The patient was given general anesthesia and cystectomy was performed. The healing was uneventful, and there has been no evidence of recurrence for 8 years since the operation.

Histologically, the lesion in the right maxilla consisted of pieces of connective tissue lined by thin parakeratinized stratified squamous epithelium lacking rete ridges. The lumen was filled with keratinous material. A diagnosis of odontogenic keratocyst was made. The wall of the cyst from the left mandible was covered by irregular, proliferating nonkeratinized stratified squamous epithelium, and a mild to moderate inflammatory reaction was seen in the thickened fibrous capsule. Deeper in the subepithelial tissue, mural proliferation of well-differentiated squamous epithelial islands was noted (Fig. 2). These squamous islands showed no atypia and lacked the columnar cells that are typical of ameloblastoma. There were microscopic foci of central cystic degeneration and irregular calcified masses surrounded by mature keratin within the tumor islands (Fig. 3). The entire tissue block was serially sectioned, but no continuity with the lining epithelium was found. The present case met the diagnostic criteria for $\mathrm{SOT}^{[2,3]}$ and thus a histologic diagnosis of a mural SOT in a primordial cyst was made.

\section{Discussion}

SOT is a benign but locally infiltrative epithelial tumor thought to arise from the rests of Malassez in the periodontal ligament ${ }^{[2,3]}$. Clinically the lesion occurs over a wide age range. There is no sex predilection, the maxilla and mandible are equally affected, and in some cases the lesion is multicentric. Most cases have shown unilocular radiolucency surrounding the tooth roots. Recurrence seems to be rare after conser-

下山哲夫、堀江憲夫、金子貴広、鈴木円、種林康彦、小澤俊文、井出文雄 Department of Oral Surgery, Saitama Medical Center, Saitama Medical School To whom all correspondence should be addressed: Dr. Norio Horie, Department of Oral Surgery, Saitama Medical Center, Saitama Medical School, 1981 Kamoda, Kawagoe, Saitama 350, JAPAN. 
vative surgical therapy, and malignant change has never been documented ${ }^{[12]}$. Histologically, SOT shows benign squamous epithelial islands with an outer layer of flattened or cuboidal cells in a mature collagenous stroma. Central cystic degeneration and dystrophic calcification may also be noted in some islands. Based on the above features, the possible hamartomatous nature of SOT has been widely accepted ${ }^{[1,12]}$.

In 1979, Wright ${ }^{[1]}$ reported SOT-like lesions in the wall of odontogenic cysts. In the cyst wall of developmental odontogenic cysts, small islands of odontogenic epithelium are often seen. However, these appear inactive and are less numerous than mural SOTs. Up to 1994, 13 additional cases had been reported in the literature $^{[4-11]}$. Of these, 5 were dentigerous, 5 radicular, 1 residual and 2 odontogenic keratocysts. These lesions showed no tendency to evolve into solid tumors and were purely cystic in nature. Thus mural SOTs exhibit clinical, radiographic and prognostic features different from those of true SOTs ${ }^{[1,12]}$. Clinically, in the present case, the cyst with the mural SOT in the left mandible behaved no differently from the cyst without SOT in the right maxilla. Taking these observations into consideration, we agree with other workers ${ }^{[11,12]}$ that SOTs and cysts with mural SOT are separate entities. Mural SOT is thought to arise from residues or derivatives of the dental lamina within the cyst wall.

\section{Acknowledgement}

We thank Dr. Paul J. W. Stoelinga for his valuable criticism in the present case.

\section{References}

[ 1 ] Pullon, P.A., Shafer, W.G., Elzay, R.P., Kerr, D.A. and Corio, R.L.:Squamous odontogenic tumor, Oral Surg., 40, 616-630, 1975

[ 2 ] Hoffman, S., Jacoway, J.R. and Krolls, S.O.: Intraosseous and parosteal tumors of the jaws, 108-110, Armed Forces Institute of Pathology, Washington, D.C. USA, 1987

[ 3 ] Kramer, I.R.H., Pindborg, J.J. and Shear, M.: Histological typing of odontogenic tumours, 14, World Health Organization, Springer-Velag, Berlin, Germany, 1992

[ 4 ] Anneroth, G. and Hansen, L.S.: Variations in keratinizing odontogenic cysts and tumors, Oral Surg., 54, 530-546, 1982

[ 5 ] Doyle, J.L., Grodjesk, J.E., Dolinsky, H.B. and Rafel, S.S.: Squamous odontogenic tumor, J. Oral Surg., 35, 994-996, 1977

[ 6 ] Fay, J.T., Banner, J., Rothouse, L., Kolas, S., Klinger, B.J. and Sayers, R.J.: Squamous odontogenic tumors arising in odontogenic cysts, J. Oral Med., 36, 35-38, 1981

[ 7 ] Hodgkinson, D.J., Woods, J.E., Dahlin, D.C. and Tolman, D.E.: Keratocysts of the jaw, Cancer, 41, 803-813, 1978.

[ 8 ] Leventon, G.S., Happonen, R.P. and Newland, J.R.: Squamous odontogenic tumor, Amer. J. Surg. Pathol., 5, 671-677, 1981

[ 9 ] Simon, J.H.S. and Jensen, J.L.: Squamous odontogenic tumor-like proliferations in periapical cysts, $J$. Endodont, 11, 446-448, 1985

[10] Unal, T., Gomel, M. and Gunel, O.: Squamous odontogenic tumor-like islands in a radicular cyst, $J$. Oral Maxillofac. Surg., 45, 346-349, 1987

[11] Wright, J.M.: Squamous odontogenic tumorlike proliferations in odontogenic cysts, Oral Surg., 47, 354-358,1979

[12] Goldblatt, L.T., Brannon, R.B. and Ellis, G.L.: Squamous odontogenic tumor, Oral Surg., 54, 187196, 1982 


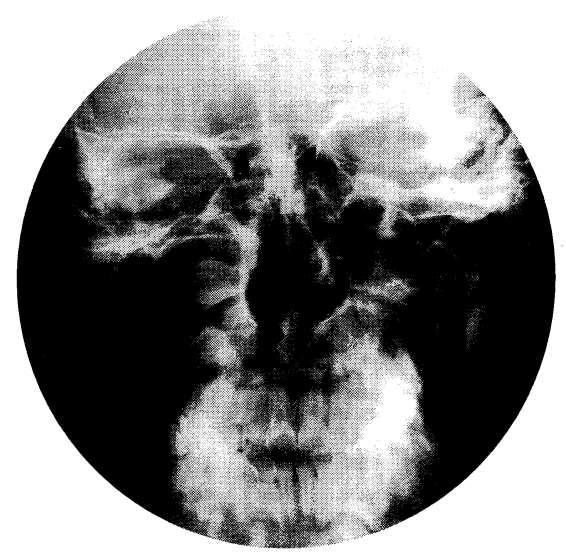

Fig. 1 Postero-anterior view showing two radiolucent lesions in the right maxilla and the left mandible

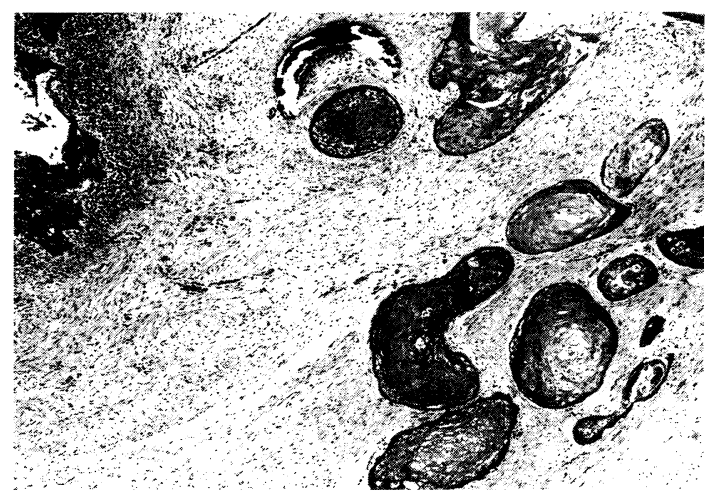

Fig. 2 Low-power photomicrograph showing numerous islands of squamous epithelium in the deep subepithelial tissue (H \& E x 40)

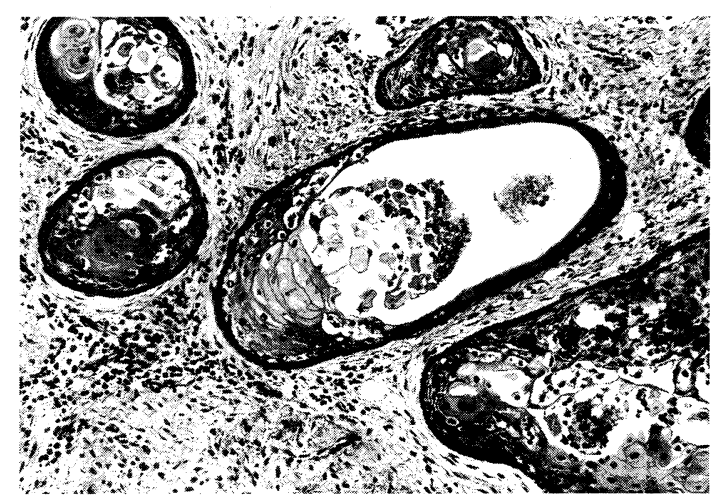

Fig. 3 High-power photomicrograph showing microcystic formations and calcifications in squamous epithelial islands (H \& E x100) 